\title{
Tijolos vazados de solo-cimento produzidos com solo da Região do Arenito Caiuá do Paraná
}

\author{
Soil-cement hollow bricks produced in the Caiuá Arenite \\ Region of Paraná
}

\author{
Vladimir José Ferrari \\ Álvaro Henrique Cândido de Souza \\ Henrique Paes Baltazar \\ Wilgner Dotto \\ José Gabriel Vieira Neto
}

Vladimir José Ferrari Universidade Estadual de Maringá Maringá - PR - Brasil

Álvaro Henrique Cândido de Souza Universidade Estadual de Maringá Cidade Gaúcha - PR - Brasil E-mail: alvarohcs@hotmail.com

Henrique Paes Baltazar Universidade Estadual de Maringá Cidade Gaúcha - PR - Brasil

Wilger Dotto Universidade Estadual de Maringá Cidade Gaúcha - PR - Brasil

José Gabriel Vieira Neto Universidade Estadual de Maringá Cidade Gaúcha - PR - Brasil

Recebido em 02/05/13 Aceito em 19/06/14

\section{Resumo}

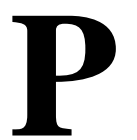

esquisas sobre materiais e técnicas de construção que considerem o contexto atual de preservação do meio ambiente e de desenvolvimento socioeconômico regional sustentável estão cada vez ganhando mais espaço na sociedade. Nesse aspecto, cita-se o caso das misturas de cimento ao solo para fins de emprego como material de construção. O presente trabalho tem por objetivo geral avaliar o solo da região do Arenito Caiuá do Noroeste do Paraná com vistas a sua incorporação com o cimento para produção de tijolos de solo-cimento. $\mathrm{O}$ efeito da substituição parcial do cimento pela cinza do bagaço da cana-de-açúcar na resistência à compressão dos tijolos e na capacidade de absorção de água também é avaliado no presente trabalho. Foram produzidos tijolos vazados de solo-cimento e de solo-cimento-cinza segundo as prescrições da NBR 10833 (ABNT, 2012a), e a propriedade mecânica de resistência a compressão simples e a capacidade de absorção de água foram determinadas segundo a NBR 8492 (ABNT, 1994). As condições exigíveis para esses parâmetros, considerando-se a aplicação de tais tijolos à execução de alvenaria sem função estrutural, são avaliadas com base nas prescrições da NBR 8491 (ABNT, 2012b). Os resultados indicam que o solo da região do Arenito Caiuá pode ser utilizado como matéria-prima para a fabricação de tijolos de solocimento.

Palavras-chave: Solo-cimento. Tijolos vazados. Resistência a compressão. Cinza.

\section{Abstract}

Research studies on materials and construction techniques that consider the current context of environmental preservation and regional sustainable socioeconomic development are increasingly gaining more space in society. In this respect, the use of mixed cement and soil for the production of construction materials must be pointed out. The main objective of this research work is to evaluate the soil of Caina Arenite Region in the northwest of the State of Parana, with the aim of using it for producing ecological soil-cement bricks. The effect of adding ash bagasse from sugar cane in the strength compression of bricks was also assessed in this investigation. Soil-cement hollow bricks were produced in accordance with the requirements of NBR 10833 (ABNT, 2012a) standard, and the compressive strength was evaluated according to NBR 8492 (ABNT, 1994) standard. The conditions required for those parameters in to application of such bricks for the non-structural masonry were evaluated based on the requirements of NBR 8491 (ABNT, 2012b). The results indicated that the soil from the Caiua Arenite Region can be effectively used as raw material for the manufacture of soilcement bricks.

Keywords: Soil-cement. Hollow bricks. Strength. Ash.

FERRARI, V. J.; SOUZA, A. H. C.; BALTAZAR, H. P.; DOTTO, W.; VIEIRA NETO, J. G. Tijolos vazados de solo-cimento 131 produzidos com solo da Região do Arenito Caiuá do Paraná. Ambiente Construído, Porto Alegre, v. 14, n. 3, p. 131-148, jul./set. 2014.

ISSN 1678-8621 Associação Nacional de Tecnologia do Ambiente Construído. 


\section{Introdução}

O solo-cimento pode ser definido como um material resultante da compactação da mistura de solo com certa quantidade de cimento Portland e água. Esse material tem sido aplicado na indústria da construção em alguns casos, como, por exemplo, base de pavimento para rodovias (ESTABRAGH; BEYTOLAHPOUR; JAVADI, 2011), proteção de encostas e aterros (ESTABRAGH; BEYTOLAHPOUR; JAVADI, 2011) e blocos para alvenarias (TENNANT; FOSTER; REDDY, 2013).

Um dos princípios envolvidos na obtenção desse material é a melhoria das propriedades (resistência e permeabilidade) do solo por meio de sua estabilização química através do cimento Portland. Segundo Houben e Guillaud (1994), a estabilização do solo consiste em modificar as características do sistema solo-água-ar com a finalidade de obter propriedades de longa duração compatíveis com uma aplicação particular. De certa forma, o processo de estabilização confere ao solo uma resposta mais adequada ante as deformações quando ele é submetido ao efeito de cargas aplicadas.

Segundo Milani e Freire (2006), na estabilização do solo com o cimento, ocorrem reações de hidratação dos silicatos e aluminatos presentes no cimento, formando um gel que preenche parte dos vazios da massa e une os grãos adjacentes do solo, conferindo-lhe resistência inicial.

Por questões ambientais, segundo Lima Junior, Willrich e Barbosa (2003), o uso do cimento como um material de estabilização tem sido criticado. Lima Junior, Willrich e Barbosa (2003) comentam que tal fato tem levado pesquisadores a aplicar outras adições minerais (cinza volante, cinza da casca de arroz, sílica ativa, etc.) em substituição ao cimento na estabilização do solo. Ainda segundo os autores, essas adições têm sílica e alumínio sob a forma amorfa, e podem reagir quimicamente com a cal que vem da hidratação do cimento, para formar compostos semelhantes aos silicatos e aluminato de cálcio hidratado.

Lima Junior, Willrich e Barbosa (2003) também comentam que outras adições minerais usadas em substituição ao cimento não têm atividade pozolânica, mas que, por conta de suas partículas, que possuem elevada finura, podem preencher os vazios entre as partículas do cimento e aumentar, consequentemente, a densidade e a resistência do solo.

Neste trabalho, investiga-se o solo da região do Arenito Caiuá, localizada no noroeste do Paraná, mais especificamente o solo do interior do Campus do Arenito da Universidade Estadual de Maringá (UEM), do Município de Cidade Gaúcha, com vistas a sua utilização na fabricação de tijolos vazados de solo-cimento. Tijolos com diferentes teores de cimento foram moldados, e sua resistência à compressão simples e a absorção de água foram avaliadas.

Na região do Arenito Caiuá existe forte presença da indústria sucroalcooleira, em que os principais subprodutos da cana-de-açúcar são a vinhaça e o bagaço. O bagaço da cana-de-açúcar é reaproveitado como combustível nas caldeiras para geração de energia. Esse bagaço é calcinado em temperaturas na faixa de $1.000{ }^{\circ} \mathrm{C}$ e tem como resultado a cinza do bagaço da cana-de-açúcar (CBC). Esse resíduo industrial pode poluir o ambiente quando descartado de forma incorreta, após a limpeza das caldeiras.

Para cada tonelada de cana-de-açúcar são gerados cerca de 250 quilos (25\%) de bagaço, que, quando queimado, produz aproximadamente 6 quilos $(2,4 \%)$ de cinzas, que contêm $77 \%$ de areia de quartzo e pó de carvão. Cabe salientar que previsão total de cana-de-açúcar a ser moída para a safra 2013/2014 é de 652,02 milhões de toneladas, com aumento de $10,7 \%$ em relação à safra 2012/2013 (COMPANHIA..., 2013).

Assim, numa segunda etapa do trabalho (como estratégia para o vislumbre de uma possível destinação desse resíduo muito abundante nas usinas da região noroeste do Paraná), a CBC foi incorporada às misturas de solo-cimento com vistas à fabricação de tijolos de solo-cimentocinza. A ideia da CBC foi substituir parcialmente o cimento das misturas e fabricar tijolos vazados para avaliar sua resistência à compressão simples e sua capacidade de absorção de água.

Assim, o objetivo geral do trabalho foi o de estudar o solo da região do Arenito Caiuá do Paraná com vistas a sua incorporação com o cimento Portland para a produção de tijolos ecológicos de solo-cimento. Já os objetivos específicos do trabalho foram: produzir tijolos vazados de solo-cimento e avaliar a resistência à compressão simples e sua capacidade de absorção de água; e produzir tijolos vazados de solocimento com substituição parcial do cimento pela CBC e avaliar sua propriedade mecânica de resistência à compressão simples e sua capacidade de absorção de água. 


\section{Características do solo com vistas à produção de tijolos de solo-cimento}

\section{Coleta do solo e investigações preliminares}

O solo foi coletado sempre de uma mesma área (fonte de coleta), localizada nas dependências do Campus do Arenito, no Município de Cidade Gaúcha, PR. Na Figura 1 mostra-se o aspecto do solo da área de coleta.

As amostras coletadas do solo foram preparadas seguindo-se as recomendações descritas na NBR 6457 (ABNT, 1986a). De acordo com a NBR 10832 (ABNT, 2003a), o solo destinado à fabricação de tijolos maciços de solo-cimento com prensa manual deve atender às seguintes características:

(a) $100 \%$ passando na peneira $\mathrm{ABNT} 4,8 \mathrm{~mm}\left(\mathrm{n}^{\circ}\right.$ 4);

(b) $10 \%$ a $50 \%$ passando na peneira ABNT 0,075 $\mathrm{mm}\left(\mathrm{n}^{\mathrm{o}} 200\right)$;

(c) limite de liquidez (LL) menor ou igual a $45 \%$; e

(d) índice de plasticidade (IP) menor ou igual a $18 \%$.

Para investigar a porcentagem de material passante nas peneiras $4,8 \mathrm{~mm}$ e $0,075 \mathrm{~mm}$ foram tomados $100 \mathrm{~g}$ do solo e realizado o peneiramento, contando-se com o auxílio de um agitador mecânico de peneiras.

O solo teve $100 \%$ de sua massa passando na peneira de $4,8 \mathrm{~mm}$, o que satisfez a primeira das condições descritas anteriormente, todavia teve apenas $7,8 \%$ de material passante na peneira de $0,075 \mathrm{~mm}$. Esse valor está um pouco abaixo do limite inferior especificado como condição a ser atendida.

\section{Análise granulométrica}

O ensaio de análise granulométrica foi realizado no Laboratório de Solos do Departamento de Engenharia Civil (DEC) da UEM, seguindo-se as recomendações descritas na NBR 7181 (ABNT, 1984a). O resultado da composição granulométrica do solo é indicado na Figura 2, dispondo-se, na abscissa, os diâmetros das partículas em escala logarítmica e, na ordenada, as porcentagens das partículas menores do que os diâmetros considerados (em escala aritmética).

Conforme composição mostrada na Figura 2, temse a classificação granulométrica indicada na Tabela 1. Vê-se que o solo é arenoso, como já sabido, tendo $78 \%$ de areia e $22 \%$ de teor de argila e silte.

\section{Limites de consistência}

Os ensaios para determinação dos limites de consistência do solo foram realizados no Laboratório de Solos do Departamento de Engenharia Agrícola (DEA) da UEM, seguindo-se os procedimentos descritos na NBR 7180 (ABNT, 1984b) e NBR 6459 (ABNT, 1984c).

$\mathrm{O}$ índice de plasticidade (IP) do solo foi obtido utilizando-se a Eq. 1, onde LL representa o limite de liquidez (em \%) e LP o limite de plasticidade (em \%).

$\mathrm{IP}=\mathrm{LL}-\mathrm{LP}$

Eq. 1

Com relação ao LP, verificou-se impossibilidade de se obter o cilindro de $3 \mathrm{~mm}$ de diâmetro com a amostra de solo. Sendo assim, classificada como não apresentando limite de plasticidade, ou seja, NP (não plástico). Já com relação ao LL, verificouse impossibilidade de se conseguir a abertura da ranhura quando da colocação da amostra na concha do aparelho de Casagrande. Sendo assim, foi classificada como não apresentando limite de liquidez, ou seja, NL (não líquido).

Figura 1 - Fonte de coleta do solo do Arenito Caiuá

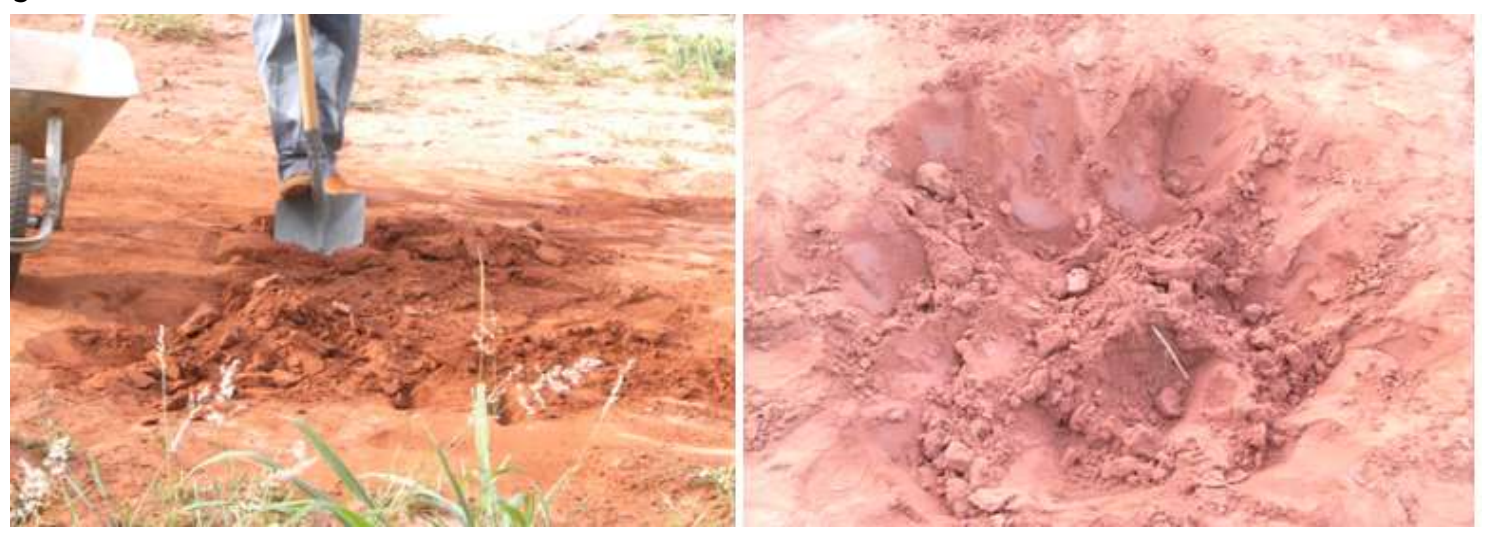


Figura 2 - Composição granulométrica do solo

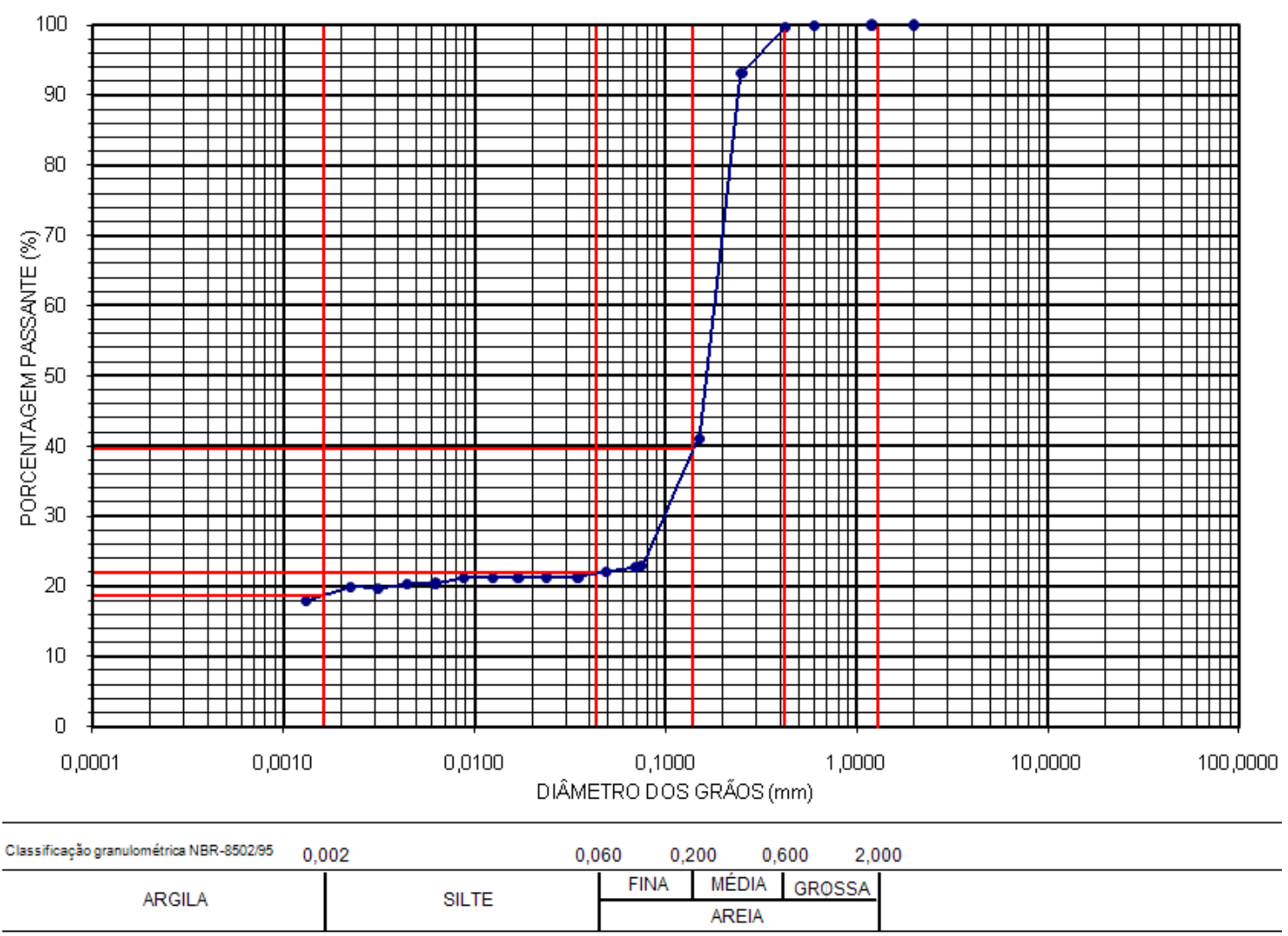

Tabela 1 - Classificação granulométrica do solo

\begin{tabular}{c|c|c|c|c|c}
\hline \multirow{2}{*}{ Solo } & \multicolumn{5}{|c}{ Classificacão Granulométrica } \\
\cline { 2 - 6 } & \multirow{2}{*}{ Argila (\%) } & \multirow{2}{*}{ Silte (\%) } & \multicolumn{4}{c}{ Areia } \\
\cline { 4 - 6 } & 19 & 3 & Fina (\%) & Média (\%) & Grossa (\%) \\
\hline Campus do Arenito & 18 & 60 & 0 \\
\hline
\end{tabular}

\section{Teste de retração}

O teste de retração consistiu em colocar a amostra de solo misturado com certa quantidade de água em uma fôrma de madeira com dimensões de $8,5 \times 60 \times 3,5 \mathrm{~cm}$. A mistura foi colocada na fôrma sem compactação e protegida do sol e chuva por 7 dias. Após esse período fez-se a leitura da retração do solo no sentido do comprimento da fôrma, utilizando-se para tanto um paquímetro. Foi obtido o valor de retração total igual a $2,5 \mathrm{~mm}$ para o solo investigado, sendo esse valor dado a partir da formação de 3 pequenas fissuras. Ainda desse valor pode-se dizer que é bem inferior ao limite de $20 \mathrm{~mm}$, recomendado pelo Ceped (CENTRO..., 1984).

\section{Ensaio de compactação do solo}

O ensaio, segundo a NBR 7182 (ABNT, 1986b), foi realizado no Laboratório de Solos do DEC da UEM com reúso de material sobre amostras preparadas com secagem prévia até a umidade higroscópica.

Na Figura 3 é mostrada a curva de compactação do solo a partir dos dados coletados no ensaio. $\mathrm{Na}$ abscissa são marcados os teores de umidade (h) e, na ordenada, as massas específicas aparentes secas correspondentes $\left(\gamma_{s}\right)$. Vê-se que a umidade ótima correspondente ao solo é igual a 9,3\%.

\section{Ensaio de compactação das misturas de solo-cimento}

O método de ensaio "A" prescrito na NBR 12023 (ABNT, 1992b) foi o utilizado para realizar o ensaio de compactação das misturas de solocimento. Para definir o teor de cimento, em massa, a ser misturado ao solo para realizar o ensaio de compactação, utilizou-se como referência a Tabela 2, extraída da NBR 12253 (ABNT, 1992a).

A partir dos resultados até então obtidos, o solo foi classificado, segundo os parâmetros da ASTM D-

134 Ferrari, V. J.; Souza, A. H. C.; Baltazar, H. P.; Dotto, W.; Vieira Neto, J. G. 
3282 (AMERICAN..., 2009), como sendo do grupo A.2. De posse dessa informação, o teor de cimento tomado como referência inicial foi de $7 \%$. No entanto, tendo-se como objetivo a obtenção da umidade ótima da mistura de solo-cimento para outros teores de cimento, foi também selecionado um teor imediatamente abaixo $(6 \%)$ do valor de referência de $7 \%$, e outro, imediatamente acima $(8 \%)$.

Foi dada sequência aos ensaios, adicionando-se cimento (CP II - F32) às amostras de solo nos teores referentes a $6 \%, 7 \%$ e $8 \%$, em massa. O cimento foi completamente misturado ao solo, até atingir uma coloração uniforme em toda a massa, compondo, assim, a mistura seca (Figura 4).

Figura 3 - Curva de compactação do solo natural

CURVA DE COMPACTAÇÃO

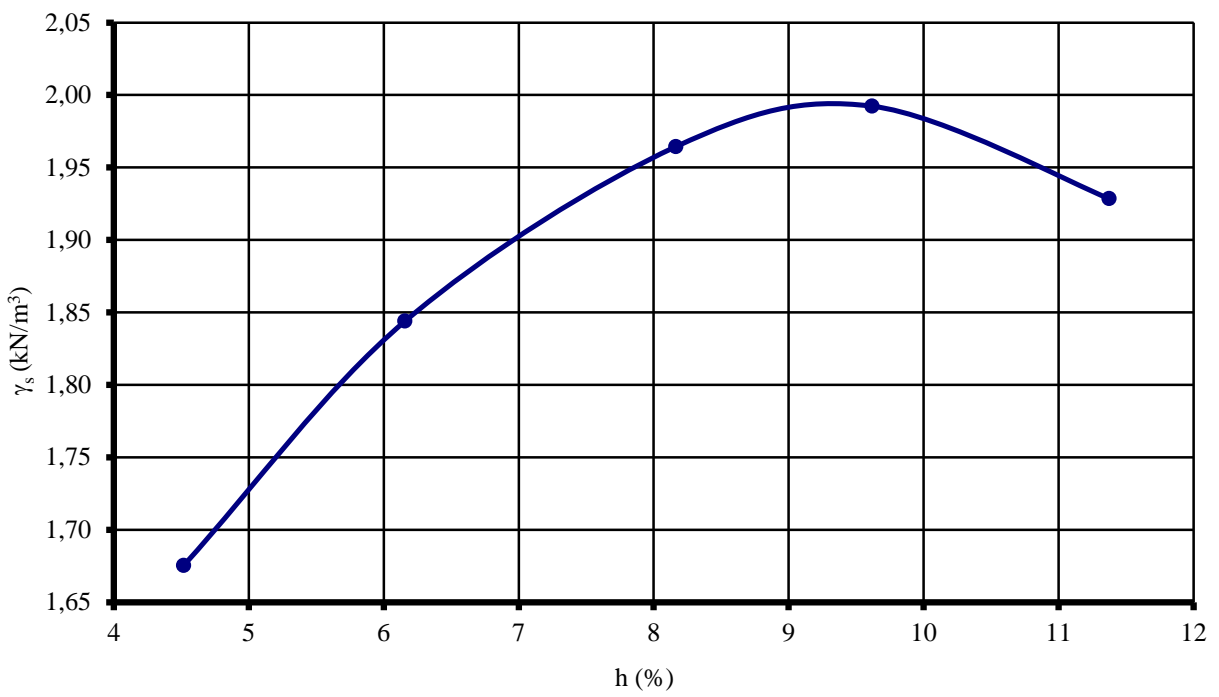

Tabela 2 - Teor de cimento sugerido para ensaio de compactação de solo-cimento

\begin{tabular}{c|c}
\hline Classificacão do solo & Teor de cimento sugerido, em massa (\%) \\
\hline A.1.a & 5 \\
A.1.b & 6 \\
A.2 & 7 \\
A.3 & 9 \\
A.4 & 10 \\
\hline
\end{tabular}

Fonte: NBR 12253 (ABNT, 1992a).

Figura 4 - Mistura seca do cimento ao solo

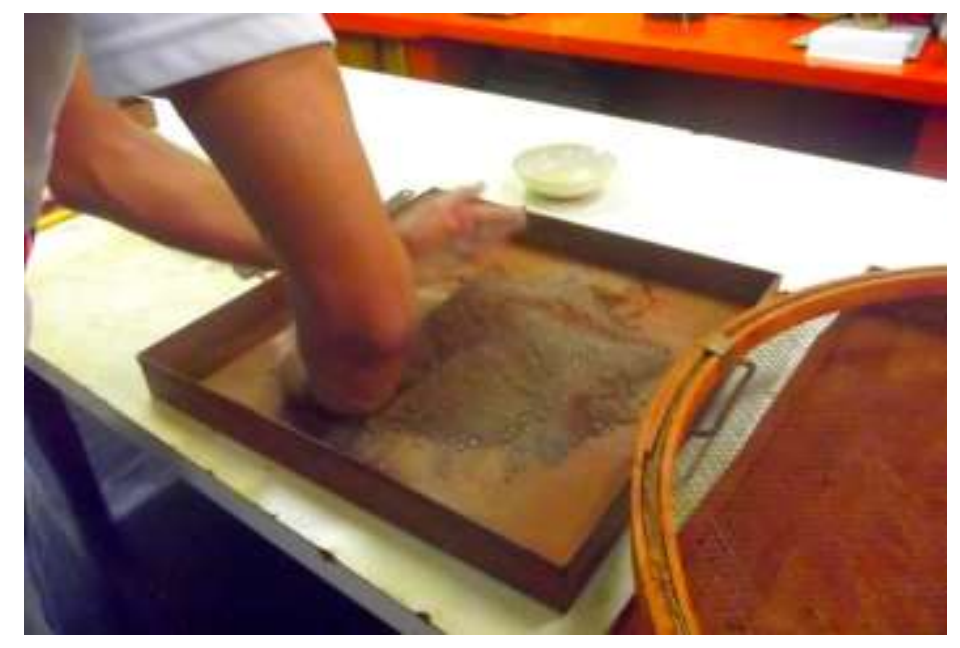


São reunidas na Figura 5 as curvas de compactação das misturas de solo-cimento, e na Tabela 3 são indicados os valores de umidade ótima e da massa específica aparente seca para cada uma das misturas analisadas.

\section{Fabricação de tijolos vazados de solo-cimento}

\section{Composições estudadas e fabricação dos tijolos}

Foram fabricados tijolos vazados de solo-cimento tendo-se como referência a norma NBR 10833 (ABNT, 2012a). Nessa fase do trabalho foi produzido um total de 27 corpos de prova de tijolos vazados de solo-cimento, distribuídos de acordo com as três diferentes composições indicadas na Tabela 4. Para cada uma das composições foram moldados 9 tijolos, que foram ensaiados para determinação da resistência à compressão simples e da capacidade de absorção de água nas idades correspondentes a 7, 14 e 21 dias.

As composições indicadas na Tabela 4 foram idealizadas com o objetivo de avaliar o efeito do aumento do teor de cimento na resistência dos tijolos vazados, como também avaliar a influência da idade dos tijolos nessas propriedades.

Os tijolos foram moldados utilizando-se uma prensa manual (Figura 6), adquirida com recursos oriundos de financiamento do projeto de pesquisa aprovado pela Fundação Araucária (órgão que apoia o desenvolvimento científico e tecnológico no estado do Paraná).

Para produção dos tijolos uma considerável quantidade de solo foi coletada e mantida no interior do Laboratório de Materiais de Construção do DEA da UEM até atingir a umidade higroscópica, sendo, em seguida, triturado e, posteriormente, peneirado, conforme mostrado na Figura 7.

Figura 5 - Curvas de compactação das misturas de solo-cimento

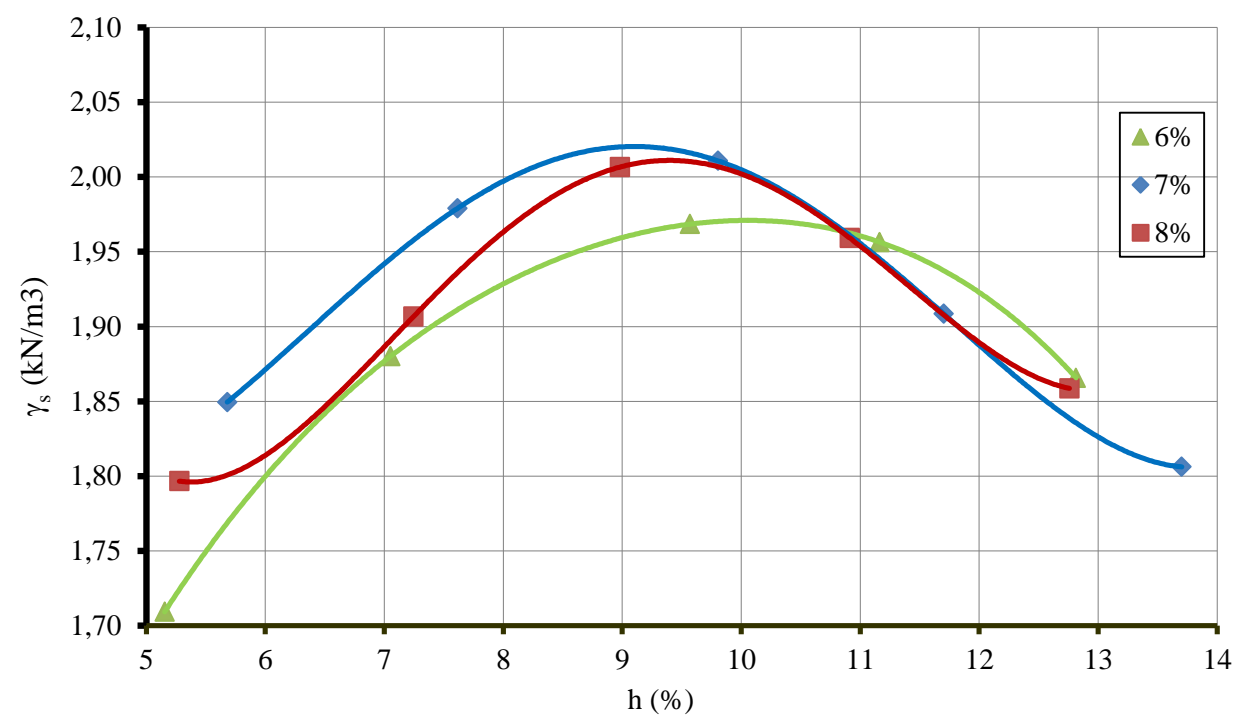

Tabela 3 - Umidade ótima e massa específica aparente seca das misturas de solo-cimento

\begin{tabular}{c|c|c}
\hline Teor de cimento da mistura & $\mathbf{h}(\%)$ & $\gamma_{\mathbf{c}}\left(\mathbf{g} / \mathbf{c m}^{\mathbf{3}}\right)$ \\
\hline $6 \%$ & 10,0 & 1,97 \\
$7 \%$ & 9,0 & 2,04 \\
$8 \%$ & 9,4 & 2,01 \\
\hline
\end{tabular}

Tabela 4 - Composições utilizadas para fabricação dos tijolos vazados

\begin{tabular}{c|c|c|c|c}
\hline \multicolumn{2}{c}{ Composições estudadas } & \multicolumn{3}{c}{ Idade (dias) } \\
\cline { 3 - 5 } \multicolumn{2}{c}{} & $\mathbf{0 7}$ & $\mathbf{1 4}$ & $\mathbf{2 1}$ \\
\hline A & $6 \%$ de adição $(100 \%$ de cimento $+0 \%$ de cinza) & 03 & 03 & 03 \\
B & $7 \%$ de adição $(100 \%$ de cimento $+0 \%$ de cinza) & 03 & 03 & 03 \\
C & $8 \%$ de adição $(100 \%$ de cimento $+0 \%$ de cinza) & 03 & 03 & 03 \\
\hline
\end{tabular}

136 Ferrari, V. J.; Souza, A. H. C.; Baltazar, H. P.; Dotto, W.; Vieira Neto, J. G. 
Figura 6 - Prensa manual para fabricação dos tijolos vazados

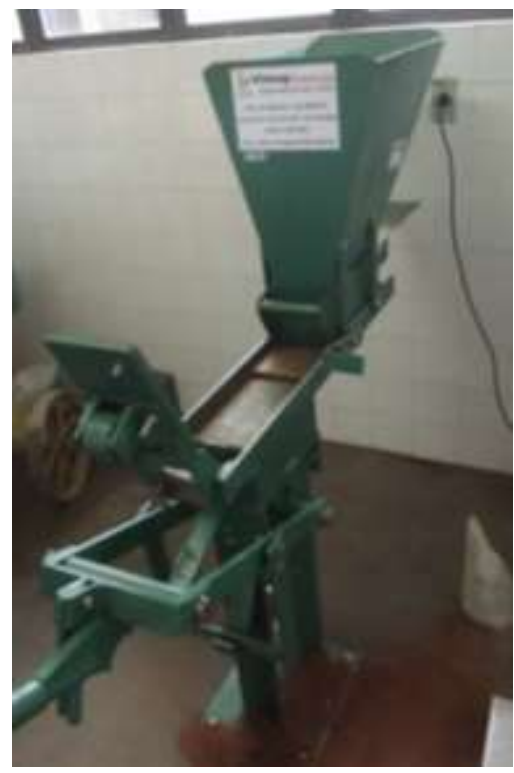

Figura 7 - Preparo do solo para produção dos tijolos

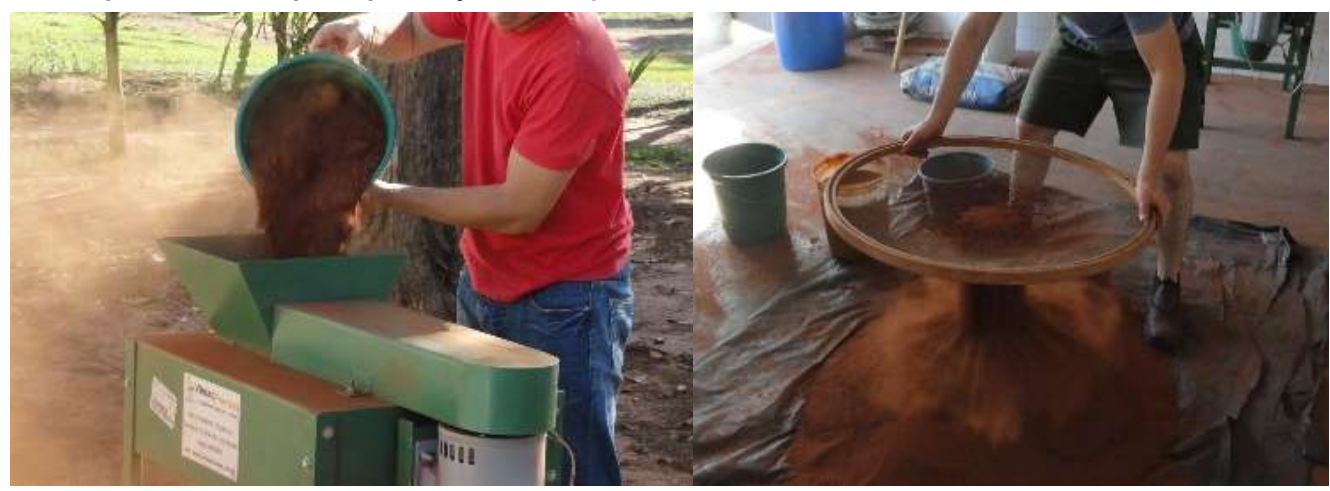

Para a produção dos tijolos foi adicionado ao solo o teor de cimento referente a cada composição em estudo e a quantidade de água conforme o valor de umidade ótima obtida para cada uma das misturas. Os materiais foram manualmente misturados até atingir uma constância de coloração, como mostrado na Figura 8. A água foi adicionada aos poucos procurando-se revirar toda a mistura até o momento em que, através de um simples teste prático, com o auxílio das próprias mãos, percebeu-se que era possível formar pequenas bolas com a mistura já umedecida.

Cada corpo de prova foi então preparado, colocando-se uma quantidade suficiente da mistura na prensa manual, na qual cada um dos tijolos foi moldado. Na Figura 9 mostra-se o tijolo logo após a moldagem e seu aspecto após $24 \mathrm{~h}$ decorridas da moldagem.

Após a moldagem cada tijolo foi armazenado em uma bancada no interior do Laboratório, onde permaneceram sob as mesmas condições, sem a realização de nenhum processo de cura. Para realizar o ensaio de absorção de água, os tijolos foram secos em estufa elétrica entre 105 e $110{ }^{\circ} \mathrm{C}$, até constância de massa (M1). Em seguida foram imersos em água durante $24 \mathrm{~h}$, para obtenção da massa do tijolo saturado (M2). O valor da absorção de cada tijolo foi calculado pela Eq. 2.

$$
A(\%)=\frac{M_{2}-M_{1}}{M_{1}} \times 100
$$

Eq. 2

Para realizar o ensaio de compressão simples, após a retirada do tijolo da água, cada uma das duas maiores superfícies do corpo de prova foi capeada utilizando-se enxofre derretido (Figura 10). Tal procedimento foi realizado para regularizar e nivelar as superfícies, a fim de uniformizar a transferência de carga para todo o volume do tijolo durante o ensaio de resistência à compressão simples. 
Cada corpo de prova foi então levado até a prensa hidráulica para a realização do ensaio de compressão simples. A carga foi aplicada lentamente, e anotaram-se os valores referentes à ruptura do corpo de prova. Na Figura 11 mostra-se o aspecto do tijolo com o surgimento da primeira fissura e também seu aspecto no instante da ruptura.

\section{Figura 8 - Mistura de solo-cimento para a produção dos tijolos}

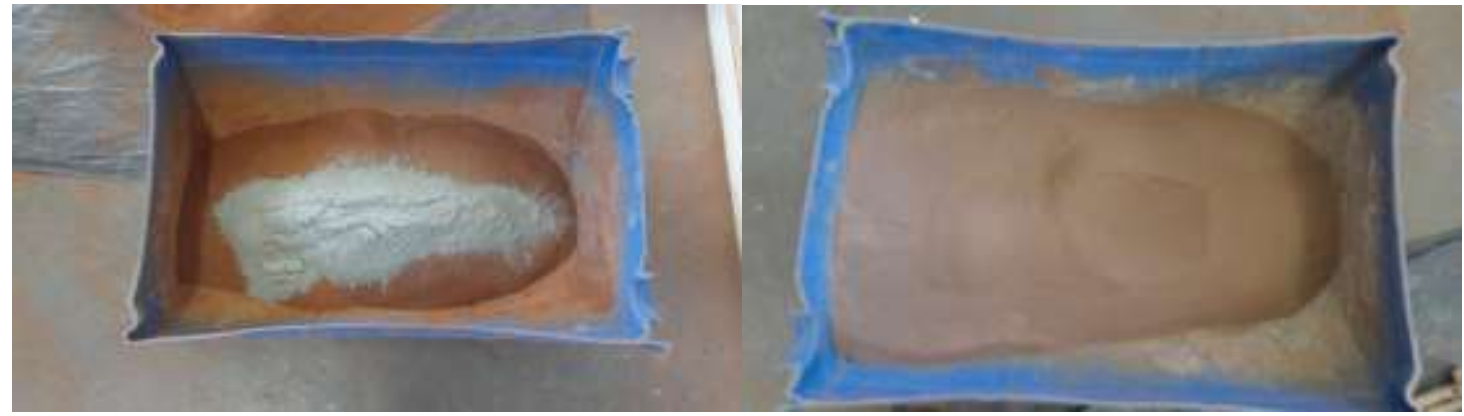

Figura 9 - Aspecto dos tijolos moldados

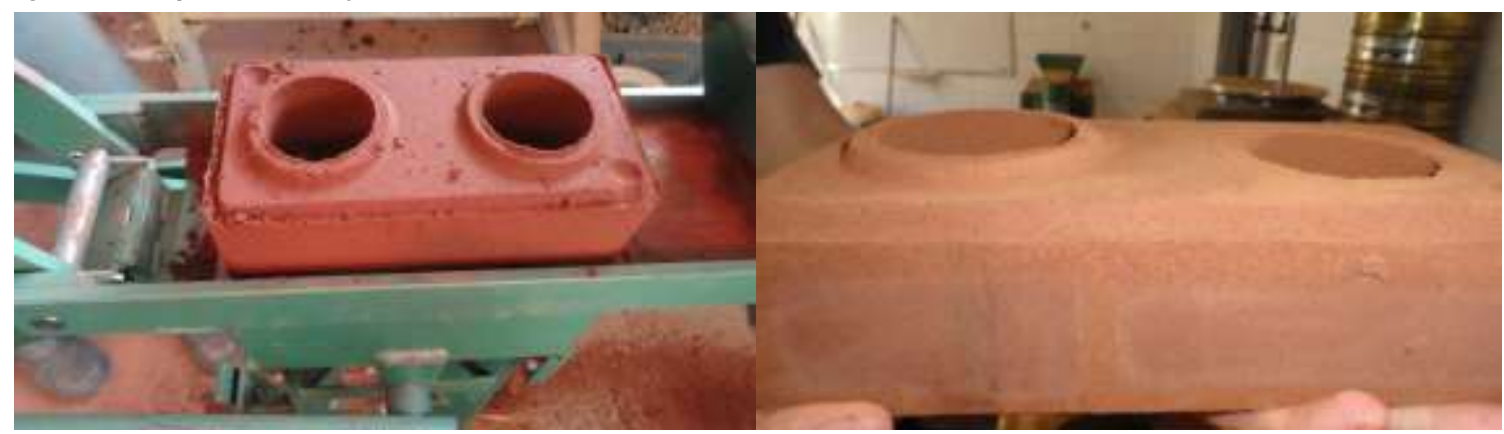

Figura 10 - Remoção das saliências do tijolo e seu aspecto após o capeamento

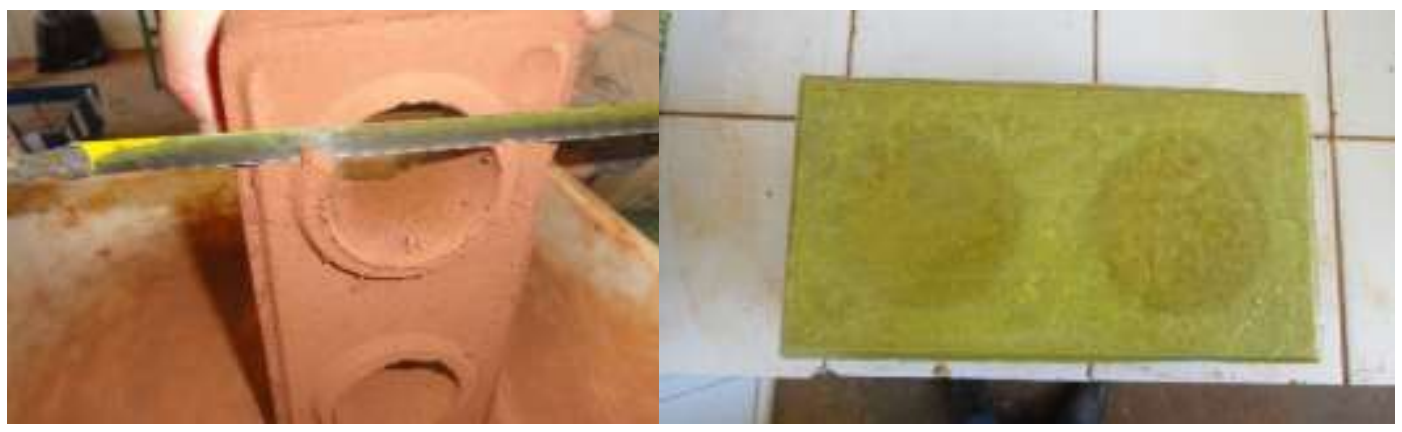

Figura 11 - Primeira fissura e ruptura do tijolo em ensaio de compressão simples

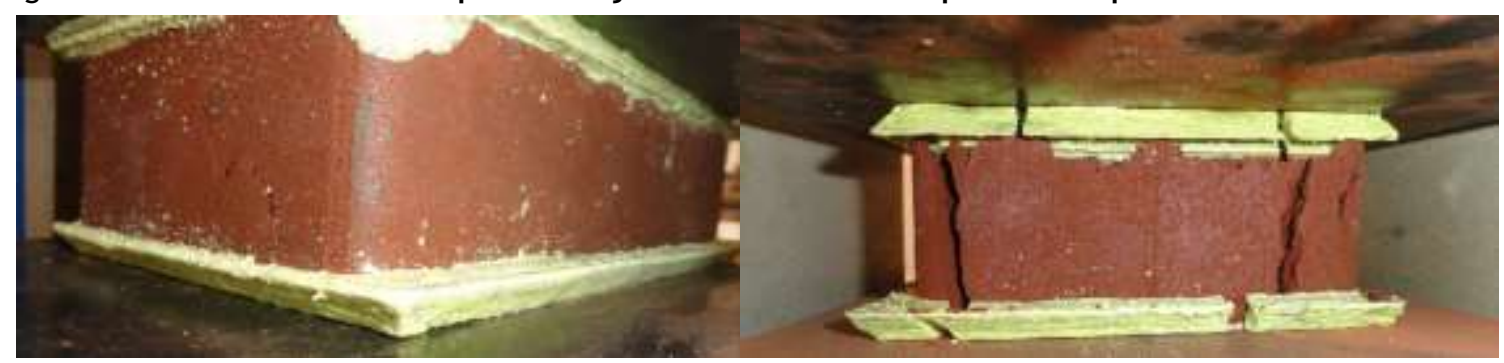

138 Ferrari, V. J.; Souza, A. H. C.; Baltazar, H. P.; Dotto, W.; Vieira Neto, J. G. 


\section{Resultados obtidos}

$\mathrm{Na}$ Tabela 5 são indicados os resultados obtidos de resistência à compressão simples para os corpos de prova das composições A, B e C para as idades de 7,14 e 21 dias.

Na Figura 12 os resultados médios da resistência à compressão simples dos tijolos são graficamente comparados. Observa-se que já aos 7 dias de idade a resistência obtida com as três composições estudadas foi superior ao valor mínimo de 2,0 $\mathrm{MPa}$, recomendado pela NBR 8491 (ABNT, $2012 b$ ). Os valores individuais que compõem a média também são superiores ao valor de 1,7 MPa, recomendado pela referida norma. Importante registrar que esses valores-limites da norma são referenciados à idade de 28 dias.

Na Figura 13 mostra-se a evolução da absorção de água dos tijolos com a idade. O gráfico, que apresenta o resultado médio de cada composição estudada, evidencia uma tendência de redução da capacidade de absorção de água dos tijolos com a evolução da idade. Essa característica é mais evidenciada entre as idades de 14 e 21 dias. Importante registrar que os valores de absorção de água dos tijolos são sempre menores do que $20 \%$, conforme prescreve a NBR 8491 (ABNT, 2012b).

Tabela 5 - Cargas e resistências dos tijolos vazados de solo-cimento

\begin{tabular}{|c|c|c|c|c|c|c|c|}
\hline \multirow{2}{*}{\multicolumn{2}{|c|}{ Composição }} & \multicolumn{3}{|c|}{ Dimensões (cm) } & \multirow{2}{*}{$\begin{array}{c}\text { Cargas }(\mathrm{kN}) \\
\mathrm{P}_{\mathrm{r}} \\
\end{array}$} & \multicolumn{2}{|c|}{ Resistências (MPa) } \\
\hline & & Largura & Comprimento & Espessura & & Máxima & Média \\
\hline \multirow{9}{*}{ 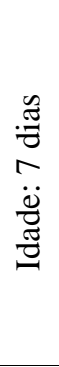 } & \multirow{3}{*}{ A } & 12,43 & 24,8 & 6,25 & 51,5 & 2,14 & \multirow{3}{*}{2,04} \\
\hline & & 12,43 & 24,8 & 6,10 & 41,4 & 1,72 & \\
\hline & & 12,44 & 24,8 & 6,36 & 55,0 & 2,29 & \\
\hline & \multirow{3}{*}{ B } & 12,42 & 24,8 & 6,26 & 60,3 & 2,51 & \multirow{3}{*}{2,41} \\
\hline & & 12,43 & 24,7 & 6,28 & 57,2 & 2,34 & \\
\hline & & 12,44 & 24,8 & 6,10 & 56,0 & 2,32 & \\
\hline & \multirow{3}{*}{$\mathrm{C}$} & 12,40 & 24,78 & 5,70 & 59,8 & 2,49 & \multirow{3}{*}{2,36} \\
\hline & & 12,42 & 24,82 & 5,43 & 52,1 & 2,17 & \\
\hline & & 12,42 & 24,80 & 5,37 & 58,2 & 2,41 & \\
\hline \multirow{9}{*}{ 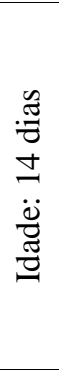 } & \multirow{3}{*}{ A } & 12,43 & 24,8 & 6,25 & 70,2 & 3,13 & \multirow{3}{*}{2,92} \\
\hline & & 12,43 & 24,8 & 6,10 & 58,2 & 2,68 & \\
\hline & & 12,44 & 24,8 & 6,36 & 70,6 & 2,96 & \\
\hline & \multirow{3}{*}{ B } & 12,42 & 24,8 & 6,26 & 80,3 & 3,41 & \multirow{3}{*}{3,14} \\
\hline & & 12,43 & 24,7 & 6,28 & 69,2 & 3,16 & \\
\hline & & 12,44 & 24,8 & 6,10 & 68,6 & 2,85 & \\
\hline & \multirow{3}{*}{$\mathrm{C}$} & 12,43 & 24,9 & 5,40 & 61,3 & 2,54 & \multirow{3}{*}{2,55} \\
\hline & & 12,40 & 24,8 & 5,55 & 61,0 & 2,54 & \\
\hline & & 12,47 & 24,8 & 5,64 & 62,4 & 2,58 & \\
\hline \multirow{9}{*}{ 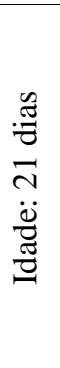 } & \multirow{3}{*}{ A } & 12,42 & 24,8 & 6,32 & 65,4 & 2,89 & \multirow{3}{*}{2,93} \\
\hline & & 12,38 & 24,8 & 6,18 & 66,1 & 2,95 & \\
\hline & & 12,40 & 24,8 & 6,30 & 46,7 & 2,97 & \\
\hline & \multirow{3}{*}{ B } & 12,41 & 24,8 & 6,14 & 67,3 & 3,36 & \multirow{3}{*}{3,18} \\
\hline & & 12,40 & 24,7 & 6,20 & 52,9 & 2,58 & \\
\hline & & 12,40 & 24,8 & 6,25 & 81,0 & 3,59 & \\
\hline & \multirow{3}{*}{ C } & 12,43 & 24,9 & 5,56 & 68,2 & 3,06 & \multirow{3}{*}{3,08} \\
\hline & & 12,44 & 24,9 & 5,44 & 63,4 & 3,03 & \\
\hline & & 12,44 & 24,9 & 5,64 & 71,8 & 3,15 & \\
\hline
\end{tabular}


Figura 12 - Evolução da resistência à compressão dos tijolos com a idade

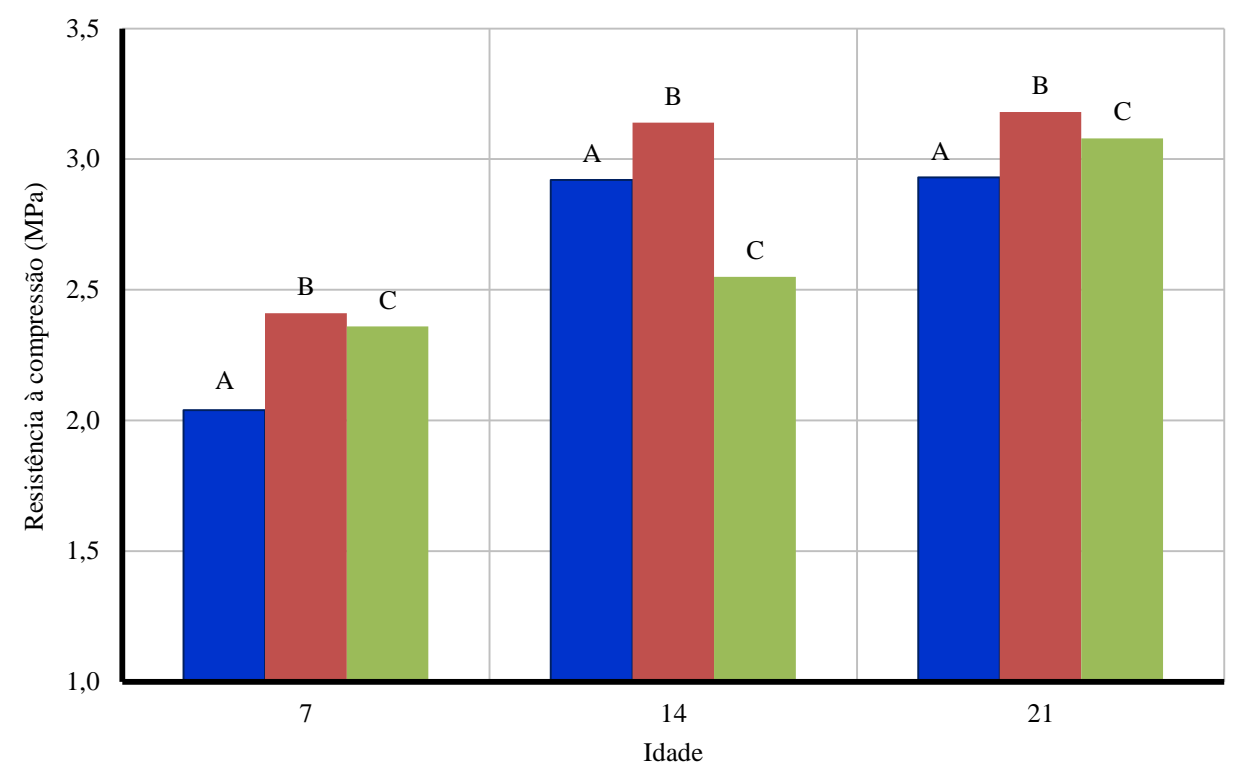

Figura 13 - Evolução da absorção de água dos tijolos com a idade

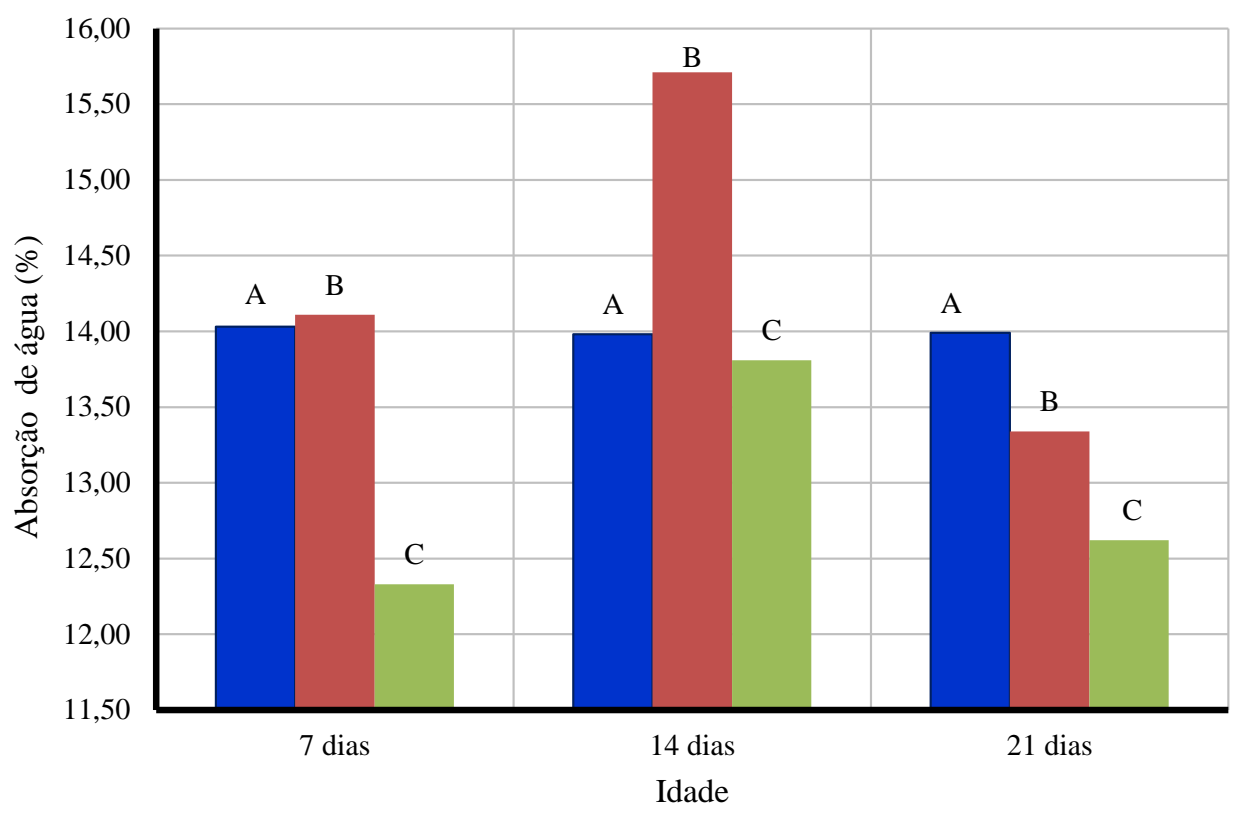

Fabricação de tijolos vazados de solo-cimento-cinza

\section{Composições estudadas e fabricação dos tijolos}

Como a resistência à compressão simples das composições estudadas no item anterior é superior à resistência mínima estabelecida pela NBR 8491 (ABNT, 2012b), foram nessa etapa do trabalho fabricados tijolos vazados de solo-cimento com a substituição parcial do cimento pela CBC. A CBC é muito abundante na região noroeste do Paraná, e o objetivo aqui foi avaliar o efeito desse resíduo sobre a resistência e a absorção de água dos tijolos e sua evolução com as idades de 7, 14 e 21 dias quando aplicado em substituição parcial ao cimento da mistura. Para tanto, foram analisadas seis novas composições, sendo moldados para cada composição 9 corpos de prova, que foram ensaiados para a determinação da resistência à compressão simples e da capacidade de absorção de água. Cada uma das composições estudadas está apresentada na Tabela 6 . 
Tabela 6 - Composições utilizadas para a fabricação dos tijolos vazados de solo-cimento-cinza

\begin{tabular}{l|l|l|l|l}
\hline \multicolumn{2}{c}{ Composiçõoes estudadas } & \multicolumn{3}{|c}{ Idade (dias) } \\
\cline { 3 - 5 } & $\mathbf{0 7}$ & $\mathbf{1 4}$ & $\mathbf{2 1}$ \\
\hline A 1 & 6\% de adição $(90 \%$ de cimento $+10 \%$ de cinza) & 03 & 03 & 03 \\
A 2 & 6\% de adição $(80 \%$ de cimento $+20 \%$ de cinza) & 03 & 03 & 03 \\
B 1 & $7 \%$ de adição $(90 \%$ de cimento $+10 \%$ de cinza) & 03 & 03 & 03 \\
B 2 & $7 \%$ de adição $(80 \%$ de cimento $+20 \%$ de cinza) & 03 & 03 & 03 \\
C 1 & $8 \%$ de adição $(90 \%$ de cimento $+10 \%$ de cinza) & 03 & 03 & 03 \\
C 2 & $8 \%$ de adição $(80 \%$ de cimento $+20 \%$ de cinza) & 03 & 03 & 03 \\
\hline
\end{tabular}

\section{Cinza do bagaço da cana-de-açúcar (CBC)}

A cinza utilizada foi proveniente da Usina Sulcroalcooleira do Distrito de Iguatemi, localizada próximo ao município de Maringá, PR. Alguns resultados provenientes da caracterização física e química estão na sequência relatados, podendo-se obter maiores detalhes por meio da consulta aos seguintes autores: Nunes et al. (2008), Liberati, Machado e Martins (2011) e Martins e Machado (2009).

Após a coleta, a amostra da cinza foi conduzida ao laboratório e seca ao ar na sombra por dois dias. A amostra foi passada pela peneira com abertura de $0,595 \mathrm{~mm}$ (malha 30). O material retido foi levado a um almofariz e destorroado com um gral revestido com borracha em sua ponta; em seguida, foi peneirado até que não houvesse material retido ou a presença de gravetos, folhas, pedras e outros resíduos considerados impurezas. Após o peneiramento, coletou-se quantidade suficiente de material para a realização dos ensaios.

$\mathrm{Na}$ Tabela 7 apresenta-se a percentagem retida acumulada da cinza conforme análise granulométrica realizada, obedecendo-se à NBR 7181 (ABNT, 1984a). Vê-se que, praticamente, a totalidade da cinza possui diâmetro entre 0,006 $\mathrm{mm}$ e $0,6 \mathrm{~mm}$.

A determinação mineralógica foi realizada pela análise de difração de raios $\mathrm{X}$, através do método do pó, realizada em um difratômero (Shimadzu, modelo D6000). Os resultados do ensaio de difração de raios $X$ (DRX) apresentam picos que evidenciam que a amostra possui material cristalino (Figura 14). Através do comparativo entre fichas cristalográficas de referência de materiais puros do JCPDS-ICCD (INTERNATIONAL..., $1996^{1}$ apud FREITAS, 2005), pode-se afirmar que há presença de mais de $98 \%$ de $\mathrm{SiO}_{2}$ cristalino (quartzo) e menos de $2 \%$ de trimidita e cristobalita.

${ }^{1}$ INTERNATIONAL CENTRE FOR DIFFRACTION DATA. [sem título]. Disponível em: <www.icdd.com/>. Acesso em: ???
A determinação da atividade pozolânica foi realizada pelo método de Chapelle Modificado (RAVERDY et al., 1980). Essa atividade é diretamente proporcional à área específica e depende da composição química do material. Dessa forma, materiais com estrutura desordenada (amorfa) apresentam maior reatividade em comparação com materiais cristalinos. Na Tabela 8 apresentam-se os resultados da atividade pozolânica da cinza. Os baixos resultados podem ser explicados pelo elevado teor de $\mathrm{SiO}_{2}$ cristalino na forma de quartzo.

Os resultados da caracterização mostram que a cinza possui alta concentração de materiais cristalinos na forma de quartzo e possui baixa área superficial. Dessa forma, a baixa atividade pozolânica da cinza no estado natural permite seu emprego apenas como enchimento em compósitos à base de cimento Portland curados ao ar.

Por não ser um material reativo, a cinza não foi utilizada para obter melhorias na resistência dos tijolos, mas, sim, com objetivo de dar destinação adequada e possível a esse resíduo, e também avaliar seu efeito na capacidade de absorção de água dos tijolos.

\section{Ensaio de compactação das misturas de solo-cimento-cinza}

Cada uma das seis novas composições de misturas foi submetida a ensaios de compactação para a obtenção do teor de umidade ótimo de cada uma. Esse teor de umidade é o que será utilizado na fabricação dos tijolos.

Os ensaios de compactação das misturas de solocimento-cinza foram realizados no Laboratório de Solos do DEC da UEM, seguindo-se o método "A" de ensaio, conforme as recomendações da NBR 12023 (ABNT, 1992b).

$\mathrm{Na}$ Figura 15 mostra-se a cinza e o cimento adicionados à amostra de solo seco. $\mathrm{O}$ cimento $(\mathrm{CP}$ II - F32) e a cinza foram misturados completamente ao solo até atingir uma coloração uniforme em toda a massa. 
Tabela 7 - Porcentagem retida de material

\begin{tabular}{c|c}
\hline 0,6 a $2 \mathrm{~mm}$ & $0 \%$ \\
\hline 0,2 a $0,6 \mathrm{~mm}$ & $50 \%$ \\
\hline 0,06 a $0,2 \mathrm{~mm}$ & $46 \%$ \\
\hline 0,002 a $0,06 \mathrm{~mm}$ & $2 \%$ \\
\hline$\leq 0,002 \mathrm{~mm}$ & $2 \%$ \\
\hline
\end{tabular}

Figura 14 - Difração de raios $X$

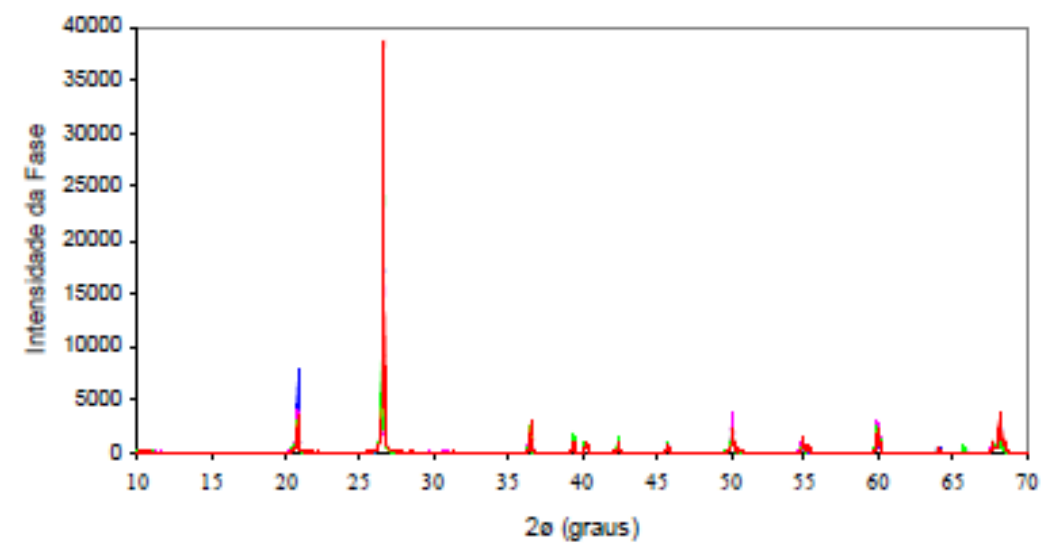

Fonte: Nunes et al. (2008).

Tabela 8 - Índice de atividade pozolânica

\begin{tabular}{c|c}
\hline Matéria orgânica & $3,55 \%$ \\
Umidade & $0,95 \%$ \\
Massa específica $\left(\mathrm{kg} / \mathrm{m}^{3}\right)$ & $2.610 \%$ \\
$\mathrm{mg} \mathrm{CaO} / \mathrm{g}$ de material & 23 \\
Área específica $\left(\mathrm{m}^{2} / \mathrm{kg}\right)$ & 5.356 \\
\hline
\end{tabular}

Figura 15 - Mistura do cimento e cinza ao solo

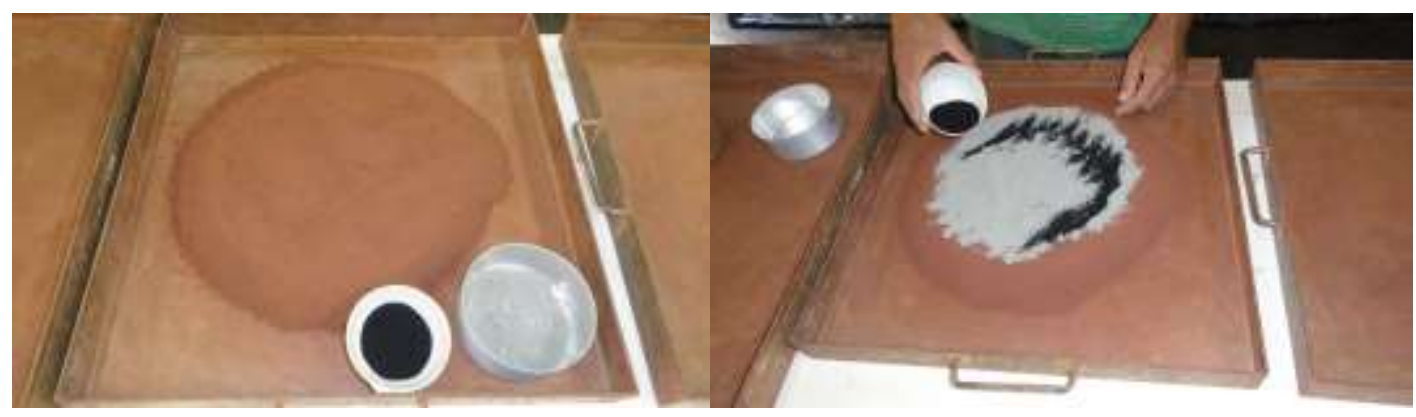

Na Tabela 9 são reunidos os valores de umidade ótima e de massa específica aparente seca, obtidos para cada uma das composições. Para efeito comparativo os resultados das composições A, B e C são reapresentados.

\section{Resistência à compressão simples dos tijolos vazados de solo-cimento- cinza}

A mesma metodologia para fabricar os tijolos vazados de solo-cimento foi a usada para fabricar os tijolos vazados de solo-cimento-cinza. A única observação foi a de incluir na mistura de solocimento a cinza na quantidade necessária para cada mistura.

Na Tabela 10 são reunidos os valores de resistência média à compressão simples para cada uma das misturas de solo-cimento-cinza. Para efeito comparativo, são reapresentados os resultados de compressão obtidos para as misturas A, B e C. Para melhor ajuste do formato da tabela, são indicados apenas os valores médios das resistências, suprimindo-se os valores individuais.

142 Ferrari, V. J.; Souza, A. H. C.; Baltazar, H. P.; Dotto, W.; Vieira Neto, J. G. 
Na Figura 16 os resultados médios da resistência à compressão simples dos tijolos aos 7 dias de idade são representados graficamente. Fica bem evidenciada a diminuição ocorrida na resistência à compressão com a substituição parcial do cimento pela cinza. Quando da substituição de $10 \%$ do cimento pela cinza na mistura, a queda na resistência dos tijolos foi de $17 \%, 31 \%$ e $22 \%$ para as composições A, B e $\mathrm{C}$ respectivamente. Porém, para $20 \%$ de substituição do cimento pela cinza, a queda na resistência dos tijolos foi em torno de $50 \%$ para as composições estudadas (A: 47\%; B: $51 \%$; e C: $49 \%$ ).

Na Figura 17 é indicada graficamente a absorção de água na idade de 7 dias dos tijolos produzidos com substituição parcial do cimento pela cinza. Nota-se que nessa idade os tijolos com substituição de $10 \%$ de cimento pela cinza das composições A e B absorveram menos água do que os tijolos sem cinza. No entanto, com a substituição de $20 \%$ de cimento pela cinza, a absorção de água foi maior do que nos tijolos com apenas $10 \%$ de substituição, mantendo-se num valor abaixo da absorção de água do tijolo sem cinza para a composição A. Já para a composição C, os resultados denotam que há sempre aumento da absorção de água com a substituição do cimento pela cinza.

Na Figura 18 os resultados médios da resistência à compressão simples dos tijolos aos 14 dias de idade são representados graficamente. Permanece evidenciada a diminuição da resistência com o aumento da substituição parcial do cimento pela cinza. Quando da substituição de $10 \%$ do cimento pelo resíduo na mistura, a queda na resistência dos tijolos foi de $57 \%, 56 \%$ e $18 \%$ para as composições $\mathrm{A}, \mathrm{B}$ e $\mathrm{C}$ respectivamente.

\section{Tabela 9 - Umidade ótima e massa específica aparente seca máxima das diversas composições} estudadas

\begin{tabular}{l|l|c|c}
\hline \multicolumn{1}{c|}{ Composição } & $\mathbf{h}_{\mathbf{o t i m a}}(\mathbf{\%})$ & $\gamma_{\mathbf{s}}\left(\mathbf{g} / \mathbf{c m}^{\mathbf{3}}\right)$ \\
\hline & Solo natural (0\% de adição) & $\mathbf{9 , 3}$ & $\mathbf{1 , 9 9}$ \\
\hline A & 6\% de adição (100\% de cimento + 0\% de cinza) & 10,0 & 1,97 \\
A.1 & 6\% de adição (90\% de cimento + 10\% de cinza) & 10,3 & 2,00 \\
A.2 & 6\% de adição (80\% de cimento + 20\% de cinza) & 10,5 & 2,01 \\
B & $7 \%$ de adição (100\% de cimento + 0\% de cinza) & 9,0 & 2,04 \\
B.1 & $7 \%$ de adição (90\% de cimento + 10\% de cinza) & 9,9 & 1,98 \\
B.2 & $7 \%$ de adição (80\% de cimento + 20\% de cinza) & 10,0 & 1,97 \\
C & $8 \%$ de adição (100\% de cimento + 0\% de cinza) & 9,4 & 2,01 \\
C.1 & $8 \%$ de adição (90\% de cimento + 10\% de cinza) & 9,7 & 1,98 \\
C.2 & $8 \%$ de adição (80\% de cimento + 20\% de cinza) & 9,9 & 1,95 \\
C.3 & $9 \%$ de adição (100\% de cimento + 0\% de cinza) & 9,4 & 2,01 \\
\hline
\end{tabular}

Nota: Legenda:

$h_{\text {ótima: }}$ umidade ótima da composição obtido através de ensaio de compactação através do cilindro Proctor em energia normal; e

$\gamma_{\mathrm{s}}:$ massa específica aparente seca.

Tabela 10 - Resistência média à compressão simples dos tijolos vazados de solo-cimento

\begin{tabular}{|c|c|c|c|c|c|c|c|c|c|}
\hline \multicolumn{10}{|c|}{ Idade: 7 dias } \\
\hline Composição & $\mathrm{A}$ & A.1 & A. 2 & B & B.1 & B. 2 & $\mathrm{C}$ & C.1 & C. 2 \\
\hline $\begin{array}{l}\text { Resistência } \\
\text { média (MPa) }\end{array}$ & 2,04 & 1,74 & 1,08 & 2,41 & 1,84 & 1,18 & 2,36 & 1,93 & 1,21 \\
\hline \multicolumn{10}{|c|}{ Idade: 14 dias } \\
\hline Composição & A & A. 1 & A. 2 & $\mathrm{~B}$ & B.1 & B. 2 & $\mathrm{C}$ & C. 1 & C. 2 \\
\hline $\begin{array}{l}\text { Resistência } \\
\text { média (MPa) }\end{array}$ & 2,92 & 1,85 & 1,14 & 3,14 & 2,01 & 1,38 & 2,55 & 2,17 & 1,20 \\
\hline \multicolumn{10}{|c|}{ Idade: 21 dias } \\
\hline Composição & $\mathrm{A}$ & A. 1 & A. 2 & B & B.1 & B. 2 & $\mathrm{C}$ & C.1 & C. 2 \\
\hline $\begin{array}{l}\text { Resistência } \\
\text { média (MPa) }\end{array}$ & 2,93 & 2,04 & 1,19 & 3,18 & 2,22 & 1,67 & 3,08 & 2,18 & 1,48 \\
\hline
\end{tabular}


Figura 16 - Resistência à compressão dos tijolos na idade de 7 dias

Resistência à compressão: tijolos vazados aos 7 dias

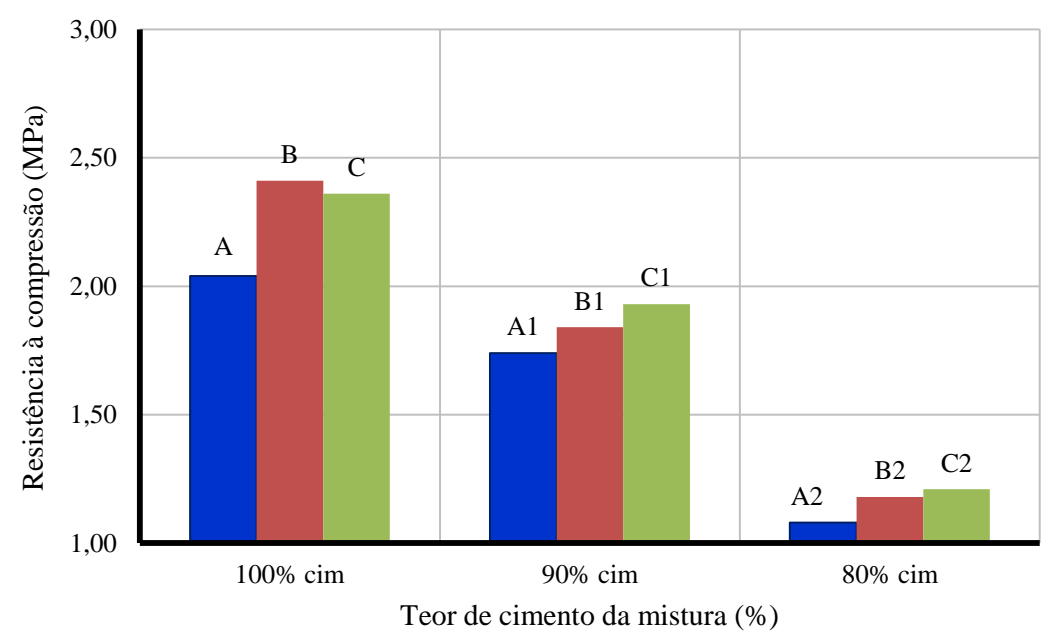

Figura 17 - Absorção de água dos tijolos na idade de 7 dias

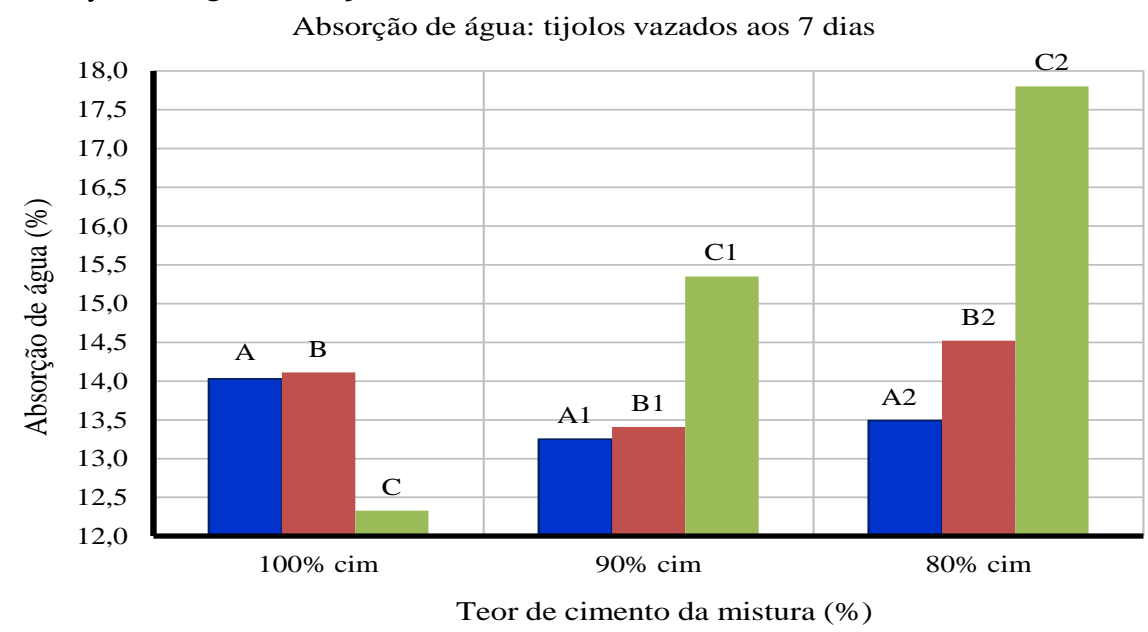

Figura 18 - Resistência a compressão dos tijolos na idade de 14 dias

Resistência à compressão: tijolos vazados aos 14 dias

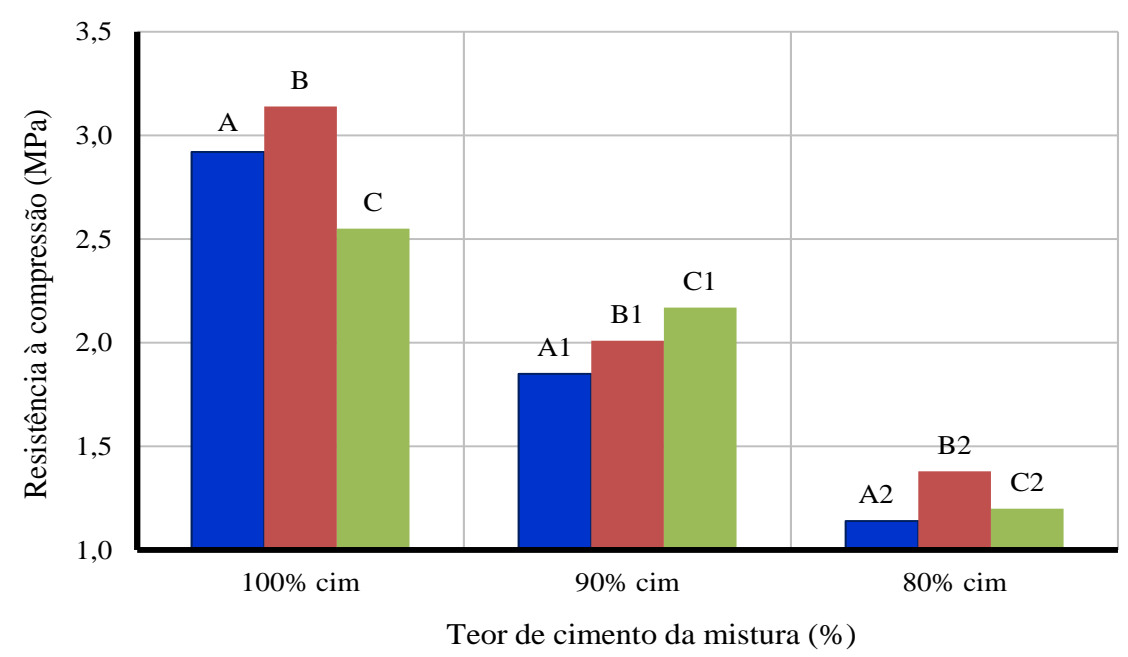

144 Ferrari, V. J.; Souza, A. H. C.; Baltazar, H. P.; Dotto, W.; Vieira Neto, J. G. 
Na Figura 19 é indicada graficamente a absorção de água na idade de 14 dias dos tijolos produzidos com substituição do cimento pela cinza. Aqui se nota que nessa idade os tijolos com substituição de $10 \%$ de cimento pela cinza absorveram menos água do que os tijolos sem a substituição do cimento (exceção para a composição contendo B, $7 \%$ de teor de cimento, na qual a absorção aumentou para $10 \%$ de cinza e apresentou decréscimo para $20 \%$ de cinza). Com a substituição de $20 \%$ de cimento pela cinza, a absorção de água nas composições $\mathrm{A}$ e $\mathrm{C}$ foram maiores do que nos tijolos com apenas $10 \%$ de substituição.

Na Figura 20 os resultados médios da resistência à compressão simples dos tijolos aos 21 dias de idade são representados graficamente. Permanece evidenciada a diminuição da resistência com o aumento da substituição do cimento pela cinza Importante registrar que na idade de 21 dias a resistência dos tijolos com substituição de $10 \%$ de cimento pela cinza superam o valor mínimo de 2,0 $\mathrm{MPa}$, estabelecido pela norma. $\mathrm{O}$ mesmo não ocorre para os tijolos contendo $20 \%$ desse resíduo. Quando da substituição de $10 \%$ do cimento pela cinza na mistura, a queda na resistência dos tijolos aos 21 dias de idade foi de $44 \%, 43 \%$ e $41 \%$ para as composições $\mathrm{A}, \mathrm{B}$ e $\mathrm{C}$ respectivamente.

Na Figura 21 é indicada graficamente a absorção de água na idade de 21 dias dos tijolos produzidos com substituição do cimento pela cinza. Nota-se que nessa idade, em geral, os tijolos com substituição do cimento pela cinza apresentaram maior capacidade de absorção de água do que os tijolos sem a substituição do cimento.

\section{Figura 19 - Absorção de água dos tijolos na idade de 14 dias}

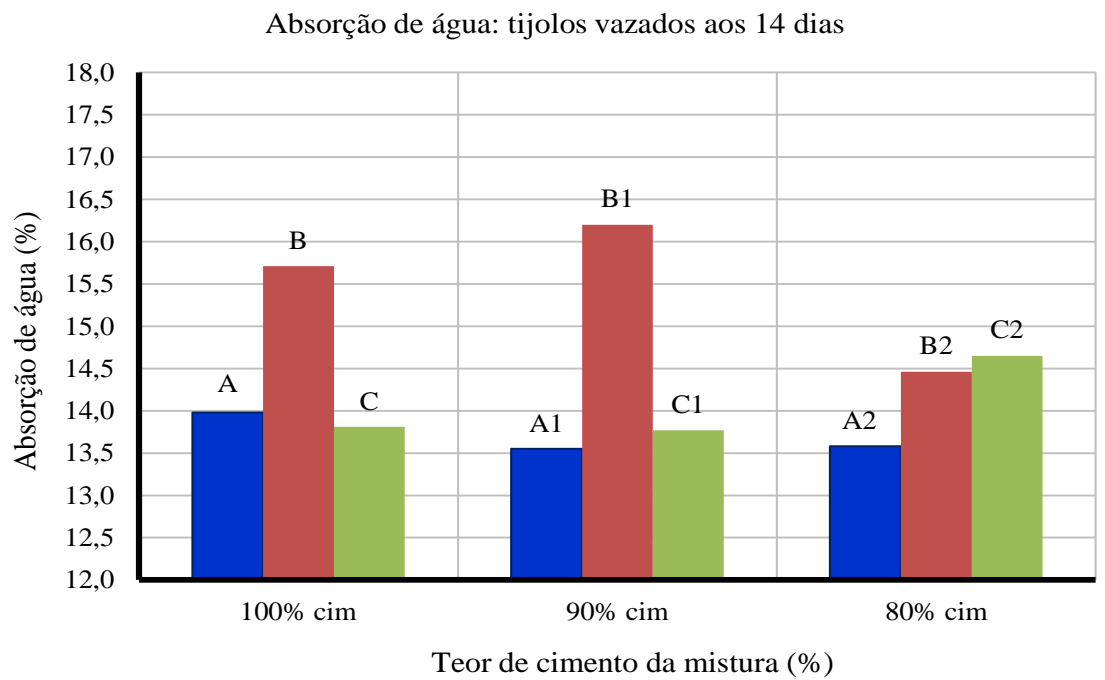

Figura 20 - Resistência à compressão dos tijolos na idade de 21 dias

Resistência à compressão: tijolos vazados aos 21 dias

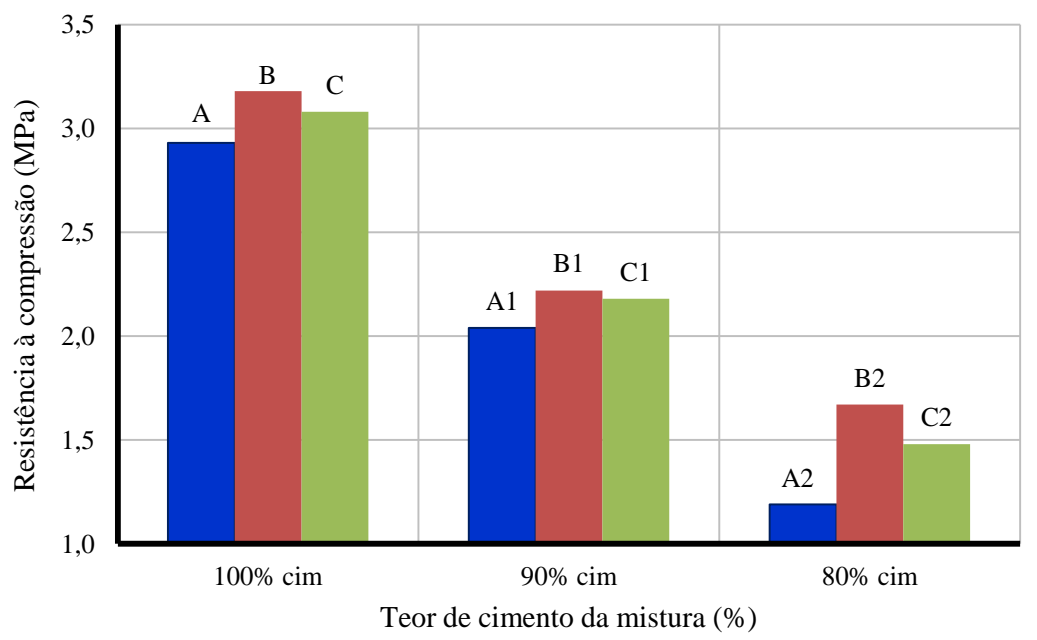


Figura 21 - Absorção de água dos tijolos na idade de 21 dias

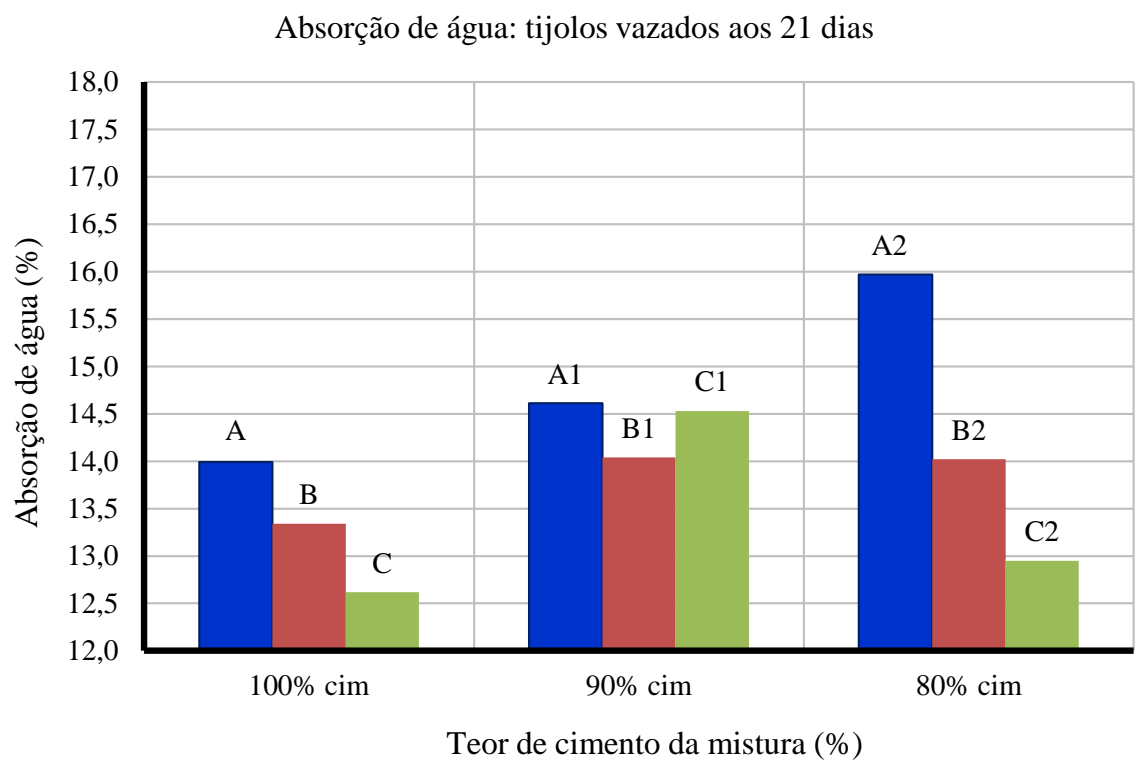

\section{Conclusões}

(a) é possível fabricar tijolos de solo-cimento empregando-se o solo da região do Arenito Caiuá, do noroeste do Paraná, mais especificamente do Município de Cidade Gaúcha;

(b) tal solo atende aos limites especificados pela norma NBR 10832 (ABNT, 2003);

(c) tijolos vazados de solo-cimento produzidos com teores de cimento, em massa, de $6 \%, 7 \%$ e $8 \%$ tiveram, já com a idade de 7 dias, sua propriedade mecânica de resistência à compressão superando o valor-limite mínimo de 2,0 MPa, estipulado pela NBR 8491 (ABNT, 2012b);

(d) os tijolos produzidos com o teor de $7 \%$ de cimento apresentaram maior resistência à compressão em todas as idades analisadas;

(e) com a substituição do cimento pela cinza nas misturas de solo-cimento, a resistência à compressão dos tijolos sempre diminuiu. A resistência dos tijolos também diminuiu com o aumento da quantidade de cinza adicionada à mistura;

(f) quando da substituição parcial de $10 \%$ de cimento pela cinza na mistura, a queda na resistência dos tijolos aos 21 dias de idade foi da ordem de $40 \%$ para todas as composições estudadas. No entanto, mesmo assim, a resistência dos tijolos manteve-se superior ao valor mínimo recomendado pela norma, podendo dessa maneira, por considerações econômicas e ambientais, incorporar a cinza numa taxa não superior a $10 \%$ para a fabricação de tijolos sem função estrutural; (g) não se recomenda utilizar 20\% de cinza em substituição ao cimento para fabricação dos tijolos. Nesse teor, a resistência à compressão obtida aos 21 dias de idade ficou inferior ao valor de 2,0 $\mathrm{MPa}$ para as três composições estudadas;

(h) mesmo com a substituição do cimento pela cinza, os teores de absorção de água dos tijolos mantiveram-se abaixo do valor máximo de $20 \%$, recomendado pela norma;

(i) ficou evidenciada tendência de redução da capacidade de absorção de água dos tijolos de solo-cimento com a evolução da idade; e

(j) com relação à absorção de água dos tijolos de solo-cimento-cinza somente na idade de 21 dias, ficou evidenciada a tendência de aumento da absorção de água com o aumento da substituição do cimento pela cinza. Já nas outras idades observou-se tendência de diminuição da absorção de água do tijolo para $10 \%$ de substituição do cimento pela cinza.

\section{Referências}

AMERICAN SOCIETY FOR TESTING AND MATERIALS. ASTM D-3282: standard practice for classification of soils and soil-aggregate mixtures for highway construction purposes. Washington, 2009.

ASSOCIAÇÃO BRASILEIRA DE NORMAS TÉCNICAS. NBR 6459: solo: determinação do limite de liquidez. Rio de Janeiro, 1984c.

146 Ferrari, V. J.; Souza, A. H. C.; Baltazar, H. P.; Dotto, W.; Vieira Neto, J. G. 
ASSOCIAÇÃO BRASILEIRA DE NORMAS TÉCNICAS. NBR 6457: amostras de solo: preparação para ensaios de compactação e ensaios de caracterização. Rio de Janeiro, 1986a.

ASSOCIAÇÃO BRASILEIRA DE NORMAS TÉCNICAS. NBR 7180: solo: determinação do limite de plasticidade. Rio de Janeiro, 1984b.

ASSOCIAÇÃO BRASILEIRA DE NORMAS TÉCNICAS. NBR 7181: solo: análise granulométrica. Rio de Janeiro, 1984a.

ASSOCIAÇÃO BRASILEIRA DE NORMAS TÉCNICAS. NBR 7182: solo: ensaio de compactação. Rio de Janeiro, 1986b.

ASSOCIAÇÃO BRASILEIRA DE NORMAS TÉCNICAS. NBR 8491: tijolo de solo-cimento: requisitos. Rio de Janeiro, 2012b.

ASSOCIAÇÃO BRASILEIRA DE NORMAS TÉCNICAS. NBR 8492: tijolo de solo-cimento: análise dimensional, determinação da resistência à compressão e da absorção de água: método de ensaio. Rio de Janeiro, 1994.

ASSOCIAÇÃO BRASILEIRA DE NORMAS TÉCNICAS. NBR 10832: fabricação de tijolo maciço de solo-cimento com utilização de prensa manual: procedimento. Rio de Janeiro, 2003.

ASSOCIAÇÃO BRASILEIRA DE NORMAS TÉCNICAS. NBR 10833: fabricação de tijolo e bloco de solo-cimento com utilização de prensa manual ou hidráulica: procedimento. Rio de Janeiro, 2012a.

ASSOCIAÇÃO BRASILEIRA DE NORMAS TÉCNICAS. NBR 12023: solo-cimento: ensaio de compactação. Rio de Janeiro, 1992 b.

ASSOCIAÇÃO BRASILEIRA DE NORMAS TÉCNICAS. NBR 12253: solo-cimento: dosagem para emprego como camada de pavimento. Rio de Janeiro, 1992a.

CENTRO DE PESQUISA E

DESENVOLVIMENTO. Manual de

Construção Com Solo-Cimento. Camaçari:

CEPED, 1984. 116 p.

COMPANHIA NACIONAL DE

ABASTECIMENTO. Acompanhamento da

Safra Brasileira: segundo levantamento da safra

2013. Disponível em:

<http://www.conab.gov.br>. Acesso em: 24 out 2013.

ESTABRAGH, A. R.; BEYTOLAHPOUR, I.; JAVADI, A. A. Effect of Resin on the Strength of Soil-Cement Mixture. Journal of Materials in Civil Engineering, v. 23, n. 7, p. 969-976, 2011.
FREITAS, E. de S. Caracterização da Cinza do Bagaço da Cana-de-Açúcar do Município dos Campos Goytacazes Para Uso na Construção Civil. Rio de Janeiro, 2005. Dissertação (Mestrado em Engenharia Civil) - Escola de Engenharia, Universidade Estadual Norte Fluminense Darcy Ribeiro, Rio de Janeiro, 2005.

HOUBEN, H.; GUILLAUD, H. Earth Construction: a compressive guide. London: Intermediate Technology Publications, 1994. 362 p.

LIBERATI, E. A. P.; MACHADO, P. H. T.; MARTINS. C. H. Resistência Mecânica de Concretos Com Substituição Parcial de Cimento Por cinza de bagaço de cana-de-açúcar. In: ENCONTRO TECNOLÓGICO DA ENGENHARIA CIVIL E ARQUITETURA, 8., Maringá, 2011. Anais... Maringá: UEM, ENTECA, 2011.

LIMA JUNIOR, H. C.; WILLRICH, F. L.; BARBOSA, N. P. Structural Behavior of Load Bearing Brick Walls of Soil-Cement With the Addition of Ground Ceramic Waste. Revista Brasileira de Engenharia Agrícola e Ambiental, v. 7, n. 3, p. 552-558, 2003.

MARTINS, C. H.; MACHADO, P. H. T. Uso da Cinza do Bagaço de Cana-de-Açúcar Como Agregado Miúdo em Argamassas. In: ENCONTRO TECNOLÓGICO DA ENGENHARIA CIVIL E ARQUITETURA, 7., Maringá, 2009. Anais... Maringá: UEM, ENTECA, 2009.

MILANI, A. P. S.; FREIRE, W. J. Características Físicas e Mecânicas de Misturas de Solo, Cimento e Casca de Arroz. Revista Brasileira de Engenharia Agrícola e Ambiental, v. 26, n. 1, p. 1-10, 2006.

NUNES, I. H. S. et al. Estudo as Características Físicas e Químicas da Cinza do Bagaço de Canade-Açúcar Para Uso na Construção. Revista Tecnológica, v. 17, p. 39-48, 2008.

RAVERDY, M. et al. Appréciation de I'Activité Pouzzolanique des Constituants Secondaires. In: CONGRÉS INTERNATIONAL DE LA CHIMIE DES CIMENTS, 7., Paris, 1980.

TENNANT, A. G.; FOSTER, C. D.; REDDY, B. V. V. Verification of Masonry Building Code to Flexural Behavior of Cement-Stabilized Soil Block. Journal of Materials in Civil Engineering, v. 25, p. 303-307, 2013. 


\section{Agradecimentos}

Os autores agradecem à Fundação Araucária, pelo financiamento proporcionado ao desenvolvimento da presente pesquisa, de grande valia para o desenvolvimento regional sustentável da região do Arenito Caiuá.

Vladimir José Ferrari

Departamento de Engenharia Civil, Centro de Tecnologia | Universidade Estadual de Maringá | Av. colombo, 5790, Zona 07 | Maringá - PR - Brasil | CEP 87020-900 | Tel.: (44) 3011-1336 | E-mail: vladimirjf@hotmail.com

\section{Álvaro Henrique Cândido de Souza}

Departamento de Engenharia Agrícola | Universidade Estadual de Maringá | Rodovia PR 482 - Km 45 | Cidade Gaúcha - PR - Brasil | CEP 87820-000 | Tel.: (44) 3675-1879 | E-mail: alvarohcs@hotmail.com

\section{Henrique Paes Baltazar}

Departamento de Engenharia Agrícola | Universidade Estadual de Maringá | E-mail: pb_henrique@yahoo.com.br

\section{Wilger Dotto}

Departamento de Engenharia Agrícola | Universidade Estadual de Maringá | E-mail: will.dtt@hotmail.com

\section{José Gabriel Vieira Neto}

Departamento de Engenharia Agrícola | Universidade Estadual de Maringá | E-mail: zeh.gvn@hotmail.com

\section{Revista Ambiente Construído}

Associação Nacional de Tecnologia do Ambiente Construído

Av. Osvaldo Aranha, $99-3^{\circ}$ andar, Centro

Porto Alegre - RS - Brasil

CEP $90035-190$

Telefone: +55 (51) 3308-4084

Fax: +55 (51) 3308-4054

www.seer.ufrgs.br/ambienteconstruido

E-mail: ambienteconstruido@ufrgs.br

148 Ferrari, V. J.; Souza, A. H. C.; Baltazar, H. P.; Dotto, W.; Vieira Neto, J. G. 